\title{
Preparation and Structural Properties of Free Films from Rapeseed Oil-Based Rigid Polyurethane-Montmorillonite Nanocomposites
}

\author{
Sergey Gaidukov, ${ }^{1}$ Ugis Cabulis, ${ }^{2}$ Karina Gromilova, ${ }^{1}$ \\ Velta Tupureina, ${ }^{1}$ and Agnese Grigalovica ${ }^{1}$ \\ ${ }^{1}$ Institute of Polymer Materials, Riga Technical University, 14/24 Azenes Strasse, Riga, LV 1048, Latvia \\ ${ }^{2}$ Latvian State Institute of Wood Chemistry, 27 Dzerbenes Strasse, Riga, LV 1006, Latvia
}

Correspondence should be addressed to Sergey Gaidukov; gaidukov@gmail.com

Received 21 February 2013; Revised 3 June 2013; Accepted 3 June 2013

Academic Editor: Yulin Deng

Copyright (C) 2013 Sergey Gaidukov et al. This is an open access article distributed under the Creative Commons Attribution License, which permits unrestricted use, distribution, and reproduction in any medium, provided the original work is properly cited.

\begin{abstract}
The preparation of free standing films of biobased rigid polyurethanes (PU) from rapeseed oil (RO) and diethanolamine (DEA) polyol and its modification with organomontmorillonite (OMMT) nanoparticles are described. Heat enthalpy of the interaction during in situ mixing of RO/DEA polyol and OMMT is measured in isothermal profile. The Fourier transform infrared spectral analysis (FTIR-ATR) is used to determine the urethane group concentration and hydrogen bonds formation in PU and PU/OMMT nanocomposites. X-ray diffraction shows the formation of intercalated and exfoliated structures of OMMT. The glasstransition temperature is used to demonstrate the formation for the intercalated and exfoliated nanocomposites of an interphase with a possible compact structure and the altered polymer chain mobility. The prepared PU/OMMT nanocomposites are also characterized by the enhanced thermal degradation characteristics upon heating in air atmosphere.
\end{abstract}

\section{Introduction}

During the last decades, bioderived or biobased polymers from different initial raw materials have been widely produced and characterized $[1,2]$. The main goal of such investigations is to replace the traditional sources of raw materialsderivatives of gas and oil fossils, that is, monomers, oligomers, and resins, with the biologically based or biologically derived ones [1-4]. For example, vegetable oils [4], bacteria and microorganism source products or byproducts [5], and wood chemical technology products (cellulose, lignin, etc.) [6] can be utilized to prepare plastics. Such polymeric materials are called biobased polymers or green polymers [7]. The strategy of such a substitution is quite obvious-the ecological reasons, as well as the legislation and high costs of petrochemical raw materials [8]. This is especially important due to the expected reduction in fossil oil and gas production.
New ways of producing traditional plastics from natural vegetable oils and plant and wood derivatives are sought for. For example, biobased polyethylene terephthalate [9], polycarbonate [10], polyethylene [11], polyamide [12], epoxide oligomers [13], and polyurethanes [14] can be produced. Some of biobased polymers, for example, polyhydroxyalkanoates [15], polylactides [16], and starch [17] are fully biodegradable.

The high versatility of the polyurethane raw materials allows manufacturing a large variety of products with different structures and properties. Generally, polyurethane (PU) is fabricated by a polycondensation reaction of lowmolecular-weight components: polyols and isocyanates [14]. Recently, market and legislation trends have driven to apply environmental friendly, renewable components for production of PU. Thus, many investigations have been dedicated to the synthesis of polyols from different vegetable oils, as 
an alternative to current commercial polyols. For example, soybean [14], sunflower and rapeseed oil [18], palm kernel oil [19], castor oil [20], fatty acid [21], and fish oil [20].

The preparation of polyurethane composites filled with montmorillonite (MMT) particles is widely used to enhance the mechanical and barrier properties. However, it is still a quite important and attractive problem how to homogeneously disperse particles at the nanoscale and increase their reinforcing efficiency in the matrix. Many authors [22-25] report a significant enhancement of the mechanical characteristics mostly for the different thermoplastic polyurethane (TPU) elastomers at the expense of the addition of very stiff inorganic MMT platelets with excellent reinforcing possibilities into the soft organic matrix. biobased TPU nanocomposites are also widely investigated $[22,25,26]$. Polyurethane materials are well known mainly as rigid and flexible foams $[27,28]$. The preparation of rapeseed oil based rigid polyurethane-montmorillonite nanocomposite in the shape of free standing films and coatings is not discussed properly.

In this paper, we aim the formulation of polyurethanes with rapeseed oil-based polyols, and preparation of polyurethane composites with the properties improved by adding montmorillonite. In particular, the rapeseed-oil-based polyol is synthesized, blended with MMT nanoparticles in different concentrations, and employed in preparation of free films of rigid PU by solution casting method. We also examine structure-property relationship of the discussed material. Data of the X-ray diffraction analysis are presented, and results of the density, infrared spectroscopy, glass transition, and thermal tests of the nanocomposites prepared are reported.

\section{Experimental Section}

2.1. OMMT. Dellite 43B is an organically modified montmorillonite (OMMT) supplied by the Laviosa Chimica Mineraria S.p.A. The OMMT is derived from a naturally occurring MMT, which is specially purified and modified with a high amount of dimethyl benzyl hydrogenated tallow ammonium salt. The characteristic parameters of the OMMT used are shown in Table 1.

2.2. Rapeseed-Oil-Based Polyol. A rapeseed oil (RO) is used for synthesis of polyol in polyurethane fabrication. RO consists mainly of unsaturated fatty acids-oleic (56\%), linoleic (26\%) and linolenic acids (10\%), and others-, saturated fatty acids-palmitic (4\%) and stearic acids (2\%)-, and other fatty acids (2\%). Diethanolamide of a rapeseed oil is prepared by an amidization reaction in a flask. The rapeseed oil reacts with diethanolamine (DEA) in the presence of a zinc acetate catalyst in argon atmosphere. The polyol obtained is characterized by the RO/DEA ratio $1: 2.5$ moles, $\mathrm{OH}$ number $360 \mathrm{mg} \mathrm{KOH} / \mathrm{g}$, NH number $15 \mathrm{mg} \mathrm{KOH/g}$, density $0.970 \mathrm{~g} / \mathrm{cm}^{3}$, viscosity $710 \mathrm{mPa} \cdot \mathrm{s}$ at $25^{\circ} \mathrm{C}$, functionality $f_{n}=$ 2.4 , water content $0.04 \%$, and content of biobased component of rapeseed oil in the polyol $77 \%$. Chemical structure of prepared RO/DEA amide is shown in Figure 1.

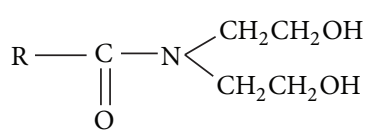

FIGURE 1: Structure of RO/DEA polyol, R-residue of saturated and unsaturated fatty acid $\mathrm{C}_{12}-\mathrm{C}_{22}$.<smiles>CCc1cc(Cc2ccc([N+](=O)[O-])cc2)ccc1[N+](=O)[O-]</smiles>

FIgURE 2: Polymeric methylene diphenylene diisocyanate (MDI).

2.3. Isocyanate. Suprasec 2651 of the Huntsman Inc. was chosen as an isocyanate. It is a polymeric methylene diphenylene diisocyanate (MDI) (see Figure 2) with NCO\% of 31.8, density of $1.20 \mathrm{~g} / \mathrm{cm}^{3}$, and viscosity of $30 \mathrm{mPa} \cdot \mathrm{s}$ at $25^{\circ} \mathrm{C}$.

2.4. Preparation of $P U$ and PU/OMMT Nanocomposites. The procedure of fabrication of PU and PU/OMMT nanocomposites consists in the following [29]. Specimens in the shape of thin films are prepared from an anhydrous toluene (Aldrich) $50 \%$ solution at a temperature of $25^{\circ} \mathrm{C}$. First, the OMMT is dispersed in toluene by mixing it with a magnetic dissolver for about $2 \mathrm{~h}$ until a $5 \mathrm{wt} . \%$ homogeneous gel-like solution is ready. Then, polyol is added, and the blend is stirred rigorously. Finally, isocyanate is added to the solution. The mixing proceeds up to the beginning of an exothermic reaction. The functional group ratio of $\mathrm{NCO} / \mathrm{OH}$ is 1.20 . The idealized structure of the synthesized $\mathrm{PU}$ is shown in Figure 3.

The resulting solutions of polyol, isocyanate, and OMMT are casted on the Teflon surface and allowed to dry up until solidification under ambient conditions for $24 \mathrm{~h}$. Then, the films are put in vacuum at $p=0.1 \mathrm{~atm}$ and $T=65^{\circ} \mathrm{C}$ for 24 hours. Thus, the films of thickness $150-200 \mu \mathrm{m}$ are ready. In total, four series of specimens with a weight content $W_{f}$ of OMMT in the amount of $0,1,3$, and $7 \mathrm{wt} . \%$ were prepared and characterized.

2.5. Wide Angle X-Ray Diffraction Analysis. The structural investigations of the OMMT and the specimens in the form of solid films were performed by the method of a wide angle Xray diffraction analysis (WAXD). The WAXD measurements were carried out on a Panalytical X'Pert PRO diffractometer at a temperature of $20^{\circ} \mathrm{C}$. The monochromatic irradiation of $\mathrm{CuK}_{\alpha}$ with a wavelength of $\lambda=0.154 \mathrm{~nm}$ in the range of diffraction angles $2 \theta$ from 2 to $15 \mathrm{deg}$ was used. The voltage was $40 \mathrm{kV}$ and the scanning rate $0.125 \mathrm{deg} / \mathrm{s}$.

2.6. Fourier Transform Infrared Analysis (FTIR-ATR). The FTIR-ATR was used to study bonding in prepared PU and PU/OMMT nanocomposites. FTIR-ATR spectra of PU films were collected at a resolution of $4 \mathrm{~cm}^{-1}$ on a Nicolet 6700 in the region of $800-4000 \mathrm{~cm}^{-1}$. Sixteen measurements for 
TABLE 1: OMMT characteristics.

\begin{tabular}{|c|c|c|c|c|}
\hline Nanoclay, OMMT & $2 \theta$, deg & $d_{001}, \mathrm{~nm}$ & Exchanged organic salt & Loss in ignition, $\%$ \\
\hline Dellite 43B & 4.8 & 1.84 & $\Longrightarrow \begin{array}{c}\mathrm{CH}_{3} \\
\mathrm{I}_{+} \\
\mathrm{C}-\mathrm{CH}_{3} \\
\left(\mathrm{CH}_{2}\right)_{n} \mathrm{CH}_{3}\end{array}$ & 35 \\
\hline
\end{tabular}<smiles>[R]C(=O)N(CCOC(=O)N1CCCCC1)CCOC(C)(C)C</smiles>

FIgURE 3: Structure of the synthesized PU.

every specimen were performed, and averaged spectrum is shown.

\subsection{Differential Scanning Calorimetry (DSC). The calorimet-} ric tests were carried out on a Mettler DSC-1 instrument. Specimens about $10 \mathrm{mg}$ in weight were scanned in three run modes: (1) heating, (2) cooling, and (3) heating, by using nitrogen as a purge gas in the temperature range from -100 to $150^{\circ} \mathrm{C}$. The first heating ran at a rate of $10^{\circ} \mathrm{C} / \mathrm{min}$, and then the specimens were cooled at $100^{\circ} \mathrm{C} / \mathrm{min}$ and repeatedly heated at $10^{\circ} \mathrm{C} / \mathrm{min}$. The glass-transition temperature $T_{g}$ and the initial $T_{g 1}$ and the final $T_{g 2}$ glass-transition temperatures, respectively, were calculated from the experimental heating curves.

Calorimetric study in the isothermal mode of the in situ mixing of polyol with OMMT is tested on SETARAM Instrumentation C80 Calorimeter. It is equipped with membrane mixing vessels that are adapted for in situ mixing and consecutive stirring of the reaction medium. Vessels with a maximal volume of $12.5 \mathrm{~mL}$ were used.

The test of the in situ mixing of RO/DEA polyol and OMMT is performed by the use of DSC in the isothermal mode to evaluate their interaction, and the test procedure consisted in the following. About $94 \mathrm{mg}$ of OMMT powder (around 5\% of the oil) was placed in the lower compartment of a clean, dried membrane mixing vessel. An amount of $2 \mathrm{~mL}$ of RO/DEA was placed in the upper compartment of the vessel. The vessel was then introduced in the measurement well of the DSC C80, previously equilibrated at $50^{\circ} \mathrm{C}$. To compensate phenomena linked to the heat of stirring, a membrane mixing vessel containing the same amount of $\mathrm{RO} / \mathrm{DEA}$ of weight about $1850 \mathrm{mg}$ in the lower chamber was placed in the reference well of the calorimeter. The system was left at $50^{\circ} \mathrm{C}$ during 45 minutes for equilibration.

After a period of 3 minutes that allows recording a flat signal for baseline determination, in situ mixing of the OMMT and the RO/DEA was achieved by manually pushing and then mechanically stirring the mixing rod of the membrane mixing vessel. The experiment was stopped after 8 hours of isotherm.
2.8. Thermogravimetric Analysis (TGA). The thermogravimetric tests were performed on a Mettler TG50 instrument. Specimens about $10 \mathrm{mg}$ in weight were heated in air up to $800^{\circ} \mathrm{C}$. The material thermal stability was evaluated from the weight-loss heating curves. The weight loss of 20,30, 50, and $75 \%$ was calculated, according to ASTM D3850, by using the Mettler original software.

2.9. Density. The density $\rho$ was determined by weighing the material in air and ethanol on Sartorius KB BA 100 electronic scales equipped with a Sartorius YDK 01 hydrostatic density measurement kit. The density $\rho$ of the specimens was estimated from (1)

$$
\rho=\frac{W_{(\mathrm{a})} \cdot\left(\rho_{\mathrm{C}_{2} \mathrm{H}_{5} \mathrm{OH}}-0.0012\right)}{0.99983 \cdot\left(W_{(\mathrm{a})}-W_{\mathrm{C}_{2} \mathrm{H}_{5} \mathrm{OH}}\right)}+0.0012,
$$

where $W_{(\mathrm{a})}$ is specimen weight in air; $W_{\left(\mathrm{C}_{2} \mathrm{H}_{5} \mathrm{OH}\right)}$ is specimen weight in ethanol; 0.0012 is density of air; $\rho_{\left(\mathrm{C}_{2} \mathrm{H}_{5} \mathrm{OH}\right)}$ is density of ethanol; 0.99983 is correction coefficient.

\section{Results and Discussion}

3.1. Calorimetric Study of the In Situ Mixing of Polyol with OMMT. The aim of this measurement is to evaluate the isothermal profile of RO/DEA while mixing with OMMT using the calorimetric technique. Figure 4 shows heat flow curves as a function of time for the mixture of component of RO/DEA and OMMT. An exothermic heat effect is recorded as soon as the mixing is initiated. This effect can be attributed to the heat of interaction of the two mixed compounds. The intensity of the exothermic phenomenon is relatively high while mixing the polyol RO/DEA with OMMT. That probably means that the interaction with the polyol is quite strong. The observed disturbances of the baseline can be attributed to the formation of OMMT agglomerates which move in the vessel during the mixing. The calculations results of the signal are as follows : heat of the enthalpy is $-6.48 \mathrm{~J} / \mathrm{g}$, intensity is $7.20 \mathrm{~mW} / \mathrm{g}$, and the kinetic is $1 \mathrm{~h}$. 


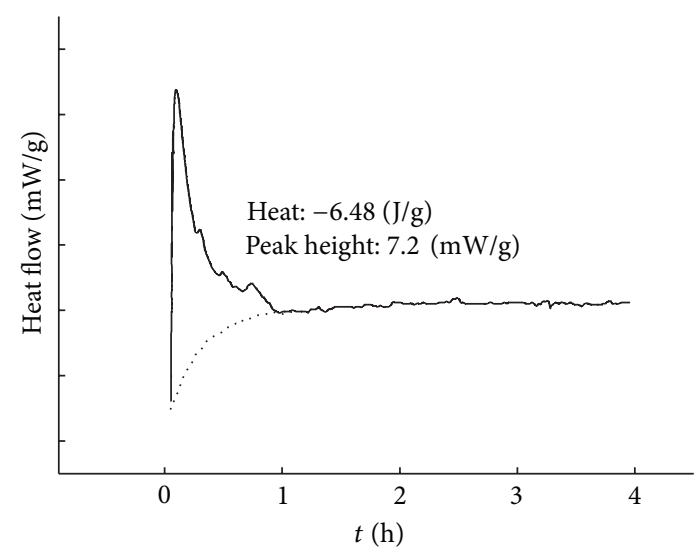

FIGURE 4: Heat flow as a function of time during mixing experiment of RO/DEA polyol with OMMT.

TABLE 2: Nanocomposites basal distance $d_{001}$ and diffraction angle $2 \theta$.

\begin{tabular}{lccc}
\hline & $W_{f}, \%$ & $d_{001}, \mathrm{~nm}$ & $2 \theta, \mathrm{deg}$ \\
\hline OMMT & & 1.84 & 4.8 \\
\hline \multirow{3}{*}{ Nanocomposite } & 1 & n.a. & n.a. \\
& 3 & 1.84 & 4.8 \\
& 7 & 1.84 & 4.8 \\
& & 3.27 & 2.7 \\
\hline
\end{tabular}

n.a.: not available.

3.2. Wide Angle X-Ray Diffraction. WAXD measurements are performed for evaluation of intercalation-exfoliation of layered particles of OMMT. The diffraction data of the neat PU and OMMT and three PU/OMMT composites with a nanoparticle content of 1, 3, and 7 wt.\% are shown in Table 2. It is seen that the diffraction pattern of the OMMT is characterized by a clear basal diffraction maximum, which corresponds to a periodically layered, placoid structure of OMMT platelet stacks, that is, packages. The characteristic basal maximum is obtained at $2 \theta=4.8^{\circ}$ and $d_{001}=$ $1.84 \mathrm{~nm}$. The neat PU is amorphous and has no diffraction pattern. The diffraction curve of a nanocomposite containing 1 wt.\% OMMT does not show a clearly indicated diffraction maximum. At a content of OMMT about $3 \mathrm{wt} . \%$, a very weak and unclear diffraction occurs, which can point to partly exfoliated platelet stacking. At an OMMT content of $7 \mathrm{wt} . \%$, or 3.2 vol. $\%$, two diffraction maxima appear at $2 \theta=4.8^{\circ}$ and $2.7^{\circ}$, which corresponds to the gallery spaces $d_{001}=1.84$ and $3.27 \mathrm{~nm}$, respectively. Thus, the particles in the form of polymer swelled stacks and the initial aggregates, that is, the platelet stacks, do exist.

3.3. Density. The structure of a nanocomposite and the interaction between the composite components can be easily evaluated from the density of the system. Ten parallel measurements were done for every composition. The density $\rho_{f}$ of the MMT is $2.52 \mathrm{~g} / \mathrm{cm}^{3}$; the experimentally measured density $\rho_{\text {poly }}$ of the polymer is $1.11 \mathrm{~g} / \mathrm{cm}^{3}$. Figure 5(a) shows the influence of the OMMT concentration on the experimental density $\rho$ of nanocomposites and the additive density $\rho^{\text {ad }}$ theoretically calculated from the additivity rule (2):

$$
\rho^{\mathrm{ad}}=\rho_{\text {poly }}\left(1-v_{f}\right)+\rho_{f} \cdot v_{f},
$$

where $\rho_{f}$ is density of the MMT, $\rho_{\text {poly }}$ is experimental density of the polymer, and $v_{f}$ is volume part of filler.

The polymer structure can be described by the apparent density $\rho_{\text {poly }}^{\prime}(3)$ of polymer (see Figure $5(\mathrm{~b})$ )

$$
\rho_{\text {poly }}^{\prime}=\frac{\rho-\rho_{f} \cdot v_{f}}{1-v_{f}},
$$

where $\rho$ is the experimental density of the nanocomposites.

The value of $\rho$ becomes nonlinear at an OMMT content above $3 \mathrm{wt}$.\%. Such a behaviour points to significant changes in the material density. At a higher weight content $W_{f}$, the deviation of $\rho$ from $\rho^{\text {ad }}$ grows. This density depression of the material depends on the mutual nanoparticle-matrix interaction and formation of the voids and structure inhomogeneities.

We believe that, at a $1-3 \mathrm{wt} . \%$ of OMMT, the polymer is converted to a boundary layer, that is, to the interphase layer around the nanoparticles, where the polymer can have the decreased free volume and closer chain packing and structuring. The formation of the interphase structure is also confirmed by the changes in glass-transition temperature of the prepared nanocomposites and by other authors due to the altered chain flexibility in the interphase [23, 30]. A further increase in $W_{f}$ leads to a significant nonlinearity of the density and heterogeneity of the matrix structure. The amount of the polymer is not enough to cover the surface of the nanoparticles, as a result of which the free volume increases, and defects are generated in the matrix. In this case, nanoparticle aggregates and voids develop, and therefore, the overall density of the composite decreases.

3.4. DSC. The results of DSC tests are presented in Figure 6 in the form of the first and second heating thermograms for specimens. All thermal curves show an endothermic transition of the second order. The PU has a broad relaxation glass-transition interval. Thus, it can be characterized by the initial temperature of transition $T_{g 1}$, the final temperature $T_{g 2}$, and the temperature $T_{g}$ at an inflection point on the curve. Table 3 summarizes the characteristic temperatures of the PU/OMMT nanocomposites. Two heatings were performed to remove the prehistory of the specimens. After the 2nd heating, the shape of the endothermic transition changes, and transition moves to the higher temperature values. It can be caused by the structure relaxation of polymer and possible additional crosslinking of chains.

The value of $T_{g}$ of the $\mathrm{PU}$ is $62^{\circ} \mathrm{C}$ at the first heating run and $110^{\circ} \mathrm{C}$ at the second one. The addition of $3 \mathrm{wt} . \%$ OMMT to the polymer increases $T_{g}$ by $26^{\circ} \mathrm{C}$. The values of $T_{g 1}$ and $T_{g 2}$ increase correspondingly. The transition interval $\left(T_{g 2}-T_{g 1}\right)$, in which the relaxation processes proceed, extends very noticeably, but a further increase in the OMMT content consequently narrows it. 


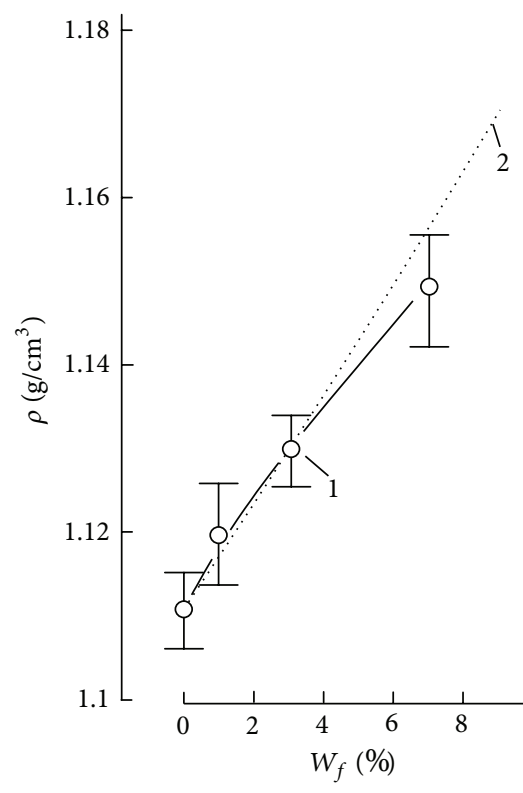

(a)

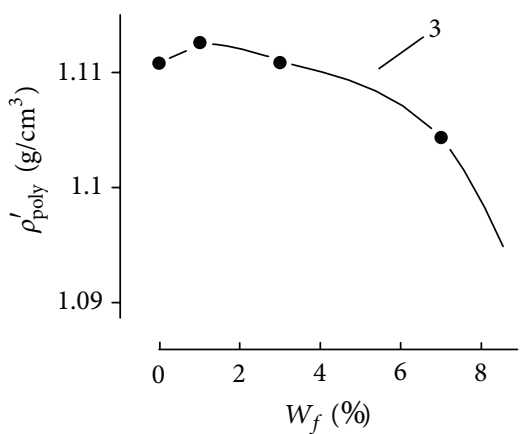

(b)

FIGURE 5: Density $\rho$ (a) of PU and PU/OMMT nanocomposites as a function of the OMMT weight content $W_{f}$ : 1 - experimental data, 2calculation by the additivity equation (2) and 3-apparent density (b) by (3).

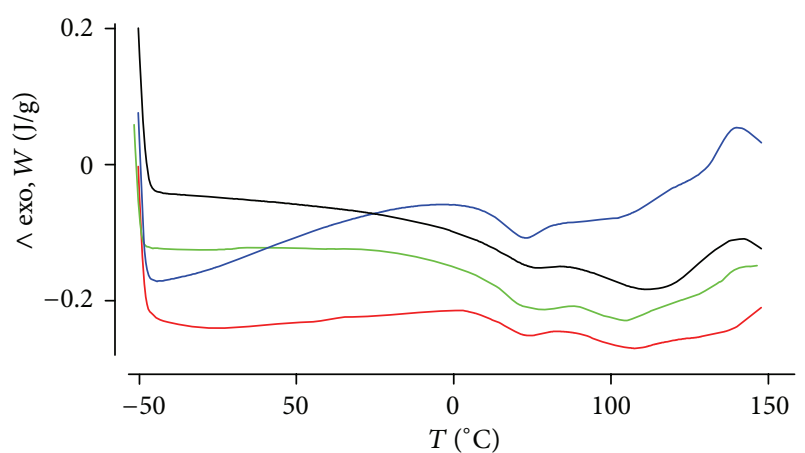

(a)

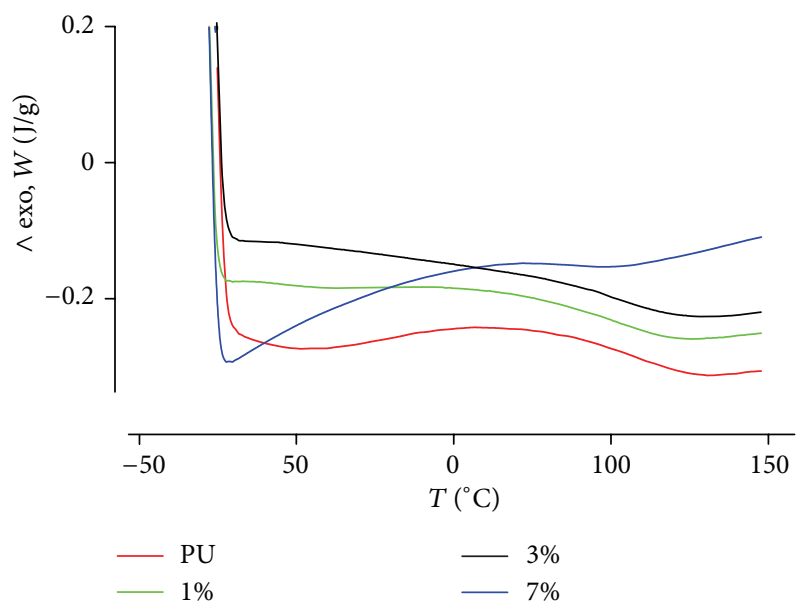

(b)

FIGURE 6: DSC curves of PU and PU/OMMT nanocomposites: (a) the 1st and (b) the 2 nd heating.
TABLE 3: The values of $T_{q}$, initial $T_{q 1}$, and final $T_{q 2}$ of the glasstransition process for the PU/OMMT nanocomposites.

\begin{tabular}{lcccccc}
\hline$W_{f}, \%$ & $T_{g 1}$ & $T_{g}$ & $T_{g 2}$ & $T_{g 2}-T_{g 1}$ & $T_{g}-T_{g 1}$ & $T_{g 2}-T_{g}$ \\
\hline \multicolumn{7}{c}{ 1st heating } \\
0 & 55 & 62 & 81 & 26 & 7 & 19 \\
1 & 37 & 71 & 106 & 69 & 34 & 36 \\
3 & 80 & 88 & 109 & 29 & 8 & 21 \\
7 & 55 & 61 & 82 & 27 & 6 & 21 \\
\hline \multicolumn{7}{c}{ 2nd heating } \\
0 & 93 & 110 & 129 & 36 & 17 & 19 \\
1 & 79 & 106 & 139 & 60 & 27 & 33 \\
3 & 95 & 116 & 136 & 41 & 20 & 21 \\
7 & 80 & 97 & 107 & 43 & 17 & 26 \\
\hline
\end{tabular}

The changes in $T_{g}$ after addition of nanoparticles can be explained by the effect of intensive interaction between the polymer matrix and nanoparticles at the interface. The modified structure of polymer in the interphase owing to the decreased mobility of macromolecule chains contacting with the surface of particles is crucial. The largest changes in the glass-transition characteristics occur at 1-3 wt.\% OMMT, which correlates with disappearance of the initial OMMT stacks, formation of the exfoliated structure, and changes in the apparent polymer density. At 7 wt.\% of OMMT, the curve looks different from the others, and the $T_{g}$ of the PU matrix decreases, and that can correspond to poor dispersionstacking and agglomeration of OMMT nanoparticles and formation of voids and defects. 


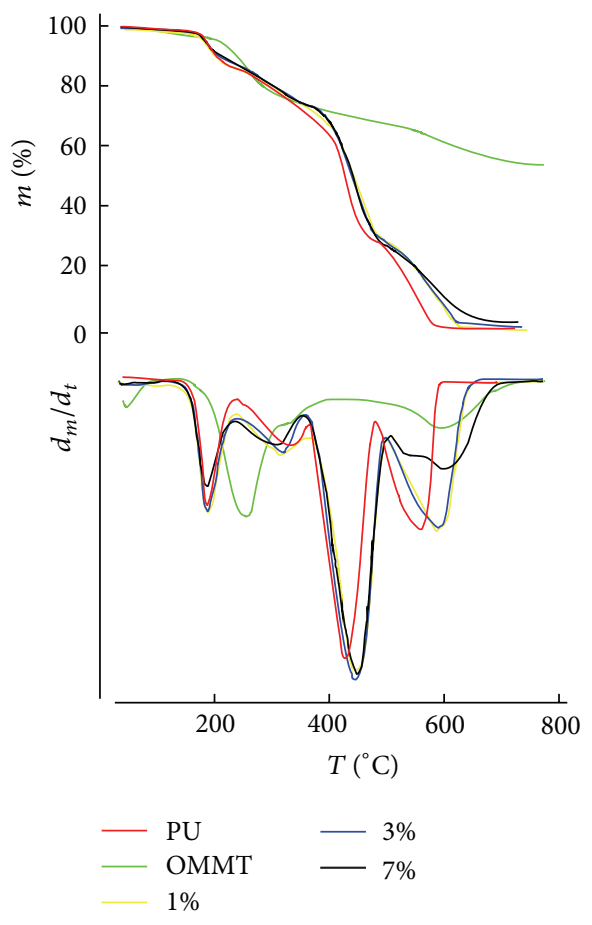

Figure 7: TGA and DTG thermograms of PU, OMMT, and PU/OMMT nanocomposites.

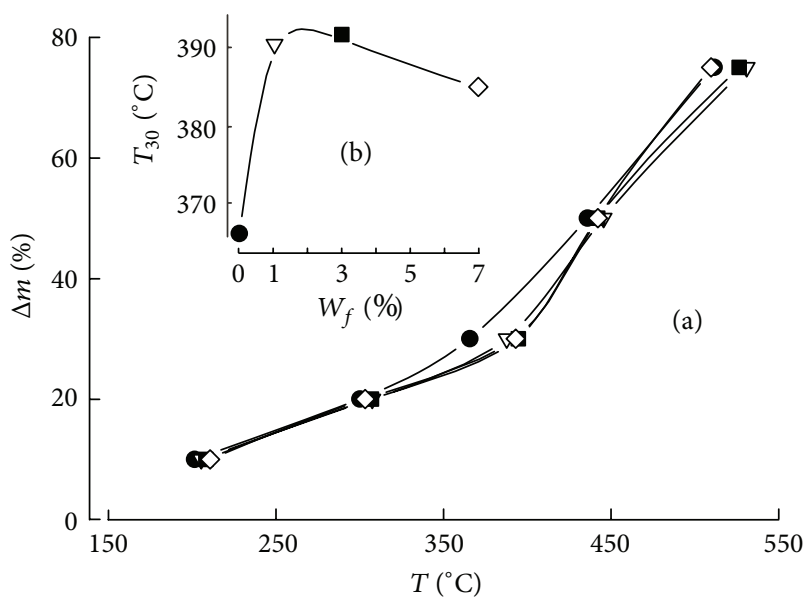

FIGURE 8: Temperature dependences of the relative weight loss $\Delta m$ of PU (•) and nanocomposites with $W_{f}=1(\nabla), 3(\boldsymbol{\bullet})$, and $7(\diamond)$ wt.\% (a); $T_{30 \%}$ as a function of $W_{f}(\mathrm{~b})$.

3.5. Thermal Properties. The integral thermograms of the TGA describing the weight loss of the specimens are shown in Figure 7. The derivative thermograms (DTG), presented in Figure 7, illustrate the differential change in weight $(\mathrm{d} m / \mathrm{d} T)$ as a function of temperature.

Heating the OMMT to $800^{\circ} \mathrm{C}$ decreases its weight by about $40 \%$. The observed decrease in the weight of OMMT in the range of $300-600^{\circ} \mathrm{C}$ is caused by decomposition of the organic modifier.
The TGA curves of a neat PU and the nanocomposites are of similar shape. The temperatures at which the specimens lose $20,30,50$, and $75 \%$ of their weight are presented in Figure 8(a). The more pronounced rise observed at $T_{30 \%}$ is shown in Figure 8(b). For the PU, $T_{30 \%}=365^{\circ} \mathrm{C}$, whereas for the nanocomposite containing only $1 \mathrm{wt} . \%$ of OMMT, $\mathrm{T}_{30 \%}=$ $388^{\circ} \mathrm{C}$.

The rise in the thermal decomposition temperature of nanocomposites is discussed in the literature [23,31]. It is mainly caused by the improved barrier properties: upon heating of the material, the placoid nanoparticles can prevent the diffusion of oxygen and remove the thermal decomposition of volatile products of the polymer [23, 30,31]. The relevant increase in the thermal stability is again more pronounced for a nanocomposite filled with 1-3 wt.\% OMMT.

3.6. FTIR-ATR. Figure 9 shows the spectra of $\mathrm{PU}$ and PU/OMMT nanocomposites. $\mathrm{NH}_{\text {bond }}$ groups are observed at $3300 \mathrm{~cm}^{-1}$. There is an absorption band at $3410 \mathrm{~cm}^{-1}$ corresponding to $\mathrm{PU}$ polymer containing free $\mathrm{NH}_{\text {free }}$ groups.

It is well known that $\mathrm{H}$-bonded $\mathrm{C}=\mathrm{O}_{\text {bond }}$ group has absorbance at $1710 \mathrm{~cm}^{-1}$, while the absorption of $-\mathrm{C}=\mathrm{O}_{\text {free }}$ is registered at $1730 \mathrm{~cm}^{-1}$.

It was found that with OMMT increasing to $3 \mathrm{wt} . \%$ in $\mathrm{PU}$, absolute absorbance values of characteristic $\mathrm{NH}_{\text {bond }}$ and $\mathrm{NH}_{\text {free }}$ groups also increases. Then, at $W_{f}=7 \%$ absorbance decreases. Thus, absorbance changes are similar to the concentration dependences of glass transition temperature and density for nanocomposites, which also decrease. Intercalation, stacking, and agglomeration of OMMT nanoparticles occur at $7 \mathrm{wt} . \%$ of OMMT. It also relates to two diffraction maxima detected by WAXD.

\section{Conclusions}

By analysing experimental results of the preparation and testing of PU/OMMT nanocomposites, we can conclude the following.

These in situ mixing tests can help in the comparison of mixing profiles of RO/DEA with OMMT nanoparticles. The quantity value of the interaction heat of the components is determined, and important in situ interaction during mixing behaviour is highlighted. It is possible to say that the RO/DEA polyol relatively strongly interacts with OMMT.

The X-ray diffraction of the PU/OMMT nanocomposites clearly indicates the exfoliation of the material at a $1 \mathrm{wt} . \%$ of OMMT. At a larger content of OMMT, the diffraction pattern is observed due to the stacking of nanoparticles. The nanocomposites are characterized by the enhanced thermal stability. The glass transition of the PU/OMMT shifts towards the region of higher temperatures, and the characteristic interval is broader in comparison with that of the PU. The largest enhancement of properties is found for the nanocomposites with 1-3 wt.\% of nanoparticles, which corresponds to their better dispersion, development of the interphase with a possibly more compact packing structure, and the altered 


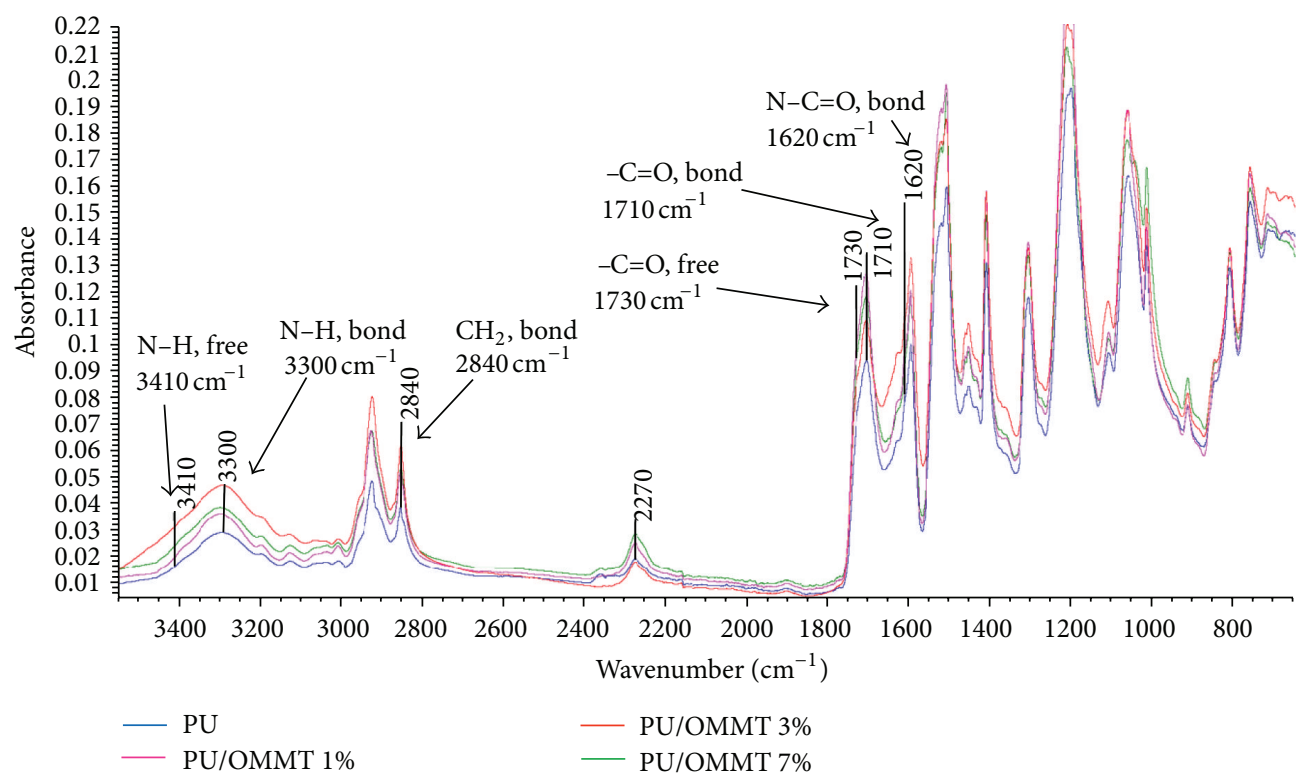

FIGURE 9: FTIR-ATR spectra of PU and PU/OMMT nanocomposites.

mobility of polymer chains. FTIR data correlates with the previous assumptions - absorbance of characteristic free amine and bonded amine and free carbonyl and bonded carbonyl groups increase up to $3 \mathrm{wt} \%$ of OMMT and decrease for PU/OMMT with 7 wt.\%.

\section{Acknowledgments}

This study was supported by the ERDF no. 2010/0214/2DP/ 2.1.1.1.0/10/APIA/VIAA/054 Development of Volatile Organic Compounds Non-Containing Sprayable Polyurethane Coatings from Renewable Raw Materials. The authors would like to thank the company SETARAM, which made the calorimetric study in the isothermal mode of the in situ mixing.

\section{References}

[1] A. Gandini, "Polymers from renewable resources: a challenge for the future of macromolecular materials," Macromolecules, vol. 41, no. 24, pp. 9491-9504, 2008.

[2] G.-Q. Chen and M. K. Patel, "Plastics derived from biological sources: present and future: a technical and environmental review," Chemical Reviews, vol. 112, no. 4, pp. 2082-2099, 2012.

[3] M. A. R. Meier, J. O. Metzger, and U. S. Schubert, "Plant oil renewable resources as green alternatives in polymer science," Chemical Society Reviews, vol. 36, no. 11, pp. 1788-1802, 2007.

[4] J. O. Metzger, "Fats and oils as renewable feedstock for chemistry," European Journal of Lipid Science and Technology, vol. 111, no. 9, pp. 865-876, 2009.

[5] M. Rinaudo, "Chitin and chitosan: properties and applications," Progress in Polymer Science, vol. 31, no. 7, pp. 603-632, 2006.

[6] R. T. Mathers, "How well can renewable resources mimic commodity monomers and polymers?" Journal of Polymer Science A, vol. 50, no. 1, pp. 1-15, 2012.
[7] E. Zini and M. Scandola, "Green composites: an overview," Polymer Composites, vol. 32, no. 12, pp. 1905-1915, 2011.

[8] W. Keim, "Petrochemicals: raw material change from fossil to biomass?" Petroleum Chemistry, vol. 50, no. 4, pp. 298-304, 2010.

[9] A. Piegat and M. Eł Fray, "Polyethylene terephthalate modification with the monomer from renewable resources," Polimery/Polymers, vol. 52, no. 11-12, pp. 885-888, 2007.

[10] B. A. J. Noordover, "Polyesters, polycarbonates and polyamides based on renewable resources," in Renewable Polymers, pp. 305354, John Wiley and Sons, 2011.

[11] A. Morschbacker, "Bio-ethanol based ethylene," Polymer Reviews, vol. 49, no. 2, pp. 79-84, 2009.

[12] Y. Deng, X. D. Fan, and J. Waterhouse, "Synthesis and characterization of soy-based copolyamides with different alpha-amino acids," Journal of Applied Polymer Science, vol. 73, pp. 1081-1088, 1999.

[13] Y. Takada, K. Shinbo, Y. Someya, and M. Shibata, "Preparation and properties of bio-based epoxy montomorillonite nanocomposites derived from polyglycerol polyglycidyl ether and $\varepsilon$ polylysine," Journal of Applied Polymer Science, vol. 113, no. 1, pp. 479-484, 2009.

[14] Z. S. Petrovic, "Polyurethanes from vegetable oils," Polymer Reviews, vol. 48, no. 1, pp. 109-155, 2008.

[15] K. Sudesh, H. Abe, and Y. Doi, "Synthesis, structure and properties of polyhydroxyalkanoates: biological polyesters," Progress in Polymer Science, vol. 25, no. 10, pp. 1503-1555, 2000.

[16] K. Fukushima and Y. Kimura, "Stereocomplexed polylactides (Neo-PLA) as high-performance bio-based polymers: their formation, properties, and application," Polymer International, vol. 55, no. 6, pp. 626-642, 2006.

[17] S. A. McGlashan and P. J. Halley, "Preparation and characterisation of biodegradable starch-based nanocomposite materials," Polymer International, vol. 52, no. 11, pp. 1767-1773, 2003.

[18] P. Rojek and A. Prociak, "Effect of different rapeseed-oilbased polyols on mechanical properties of flexible polyurethane 
foams," Journal of Applied Polymer Science, vol. 125, pp. 29362945, 2012.

[19] C. S. Lee, T. L. Ooi, C. H. Chuah, and S. Ahmad, "Rigid polyurethane foam production from palm oil-based epoxidized diethanolamides," Journal of the American Oil Chemists' Society, vol. 84, no. 12, pp. 1161-1167, 2007.

[20] H. Beneš, T. Vlček, R. Černá, J. Hromádková, Z. Walterová, and R. Svitáková, "Polyurethanes with bio-based and recycled components," European Journal of Lipid Science and Technology, vol. 114, pp. 71-83, 2012.

[21] C. Bueno-Ferrer, E. Hablot, F. Perrin-Sarazin, M. C. Garrigas, A. Jiménez, and L. Averous, "Structure and morphology of new bio-based thermoplastic polyurethanes obtained from dimeric fatty acids," Macromolecular Materials and Engineering, vol. 297, no. 8, pp. 777-784, 2012.

[22] J. Xiong, Y. Liu, X. Yang, and X. Wang, "Thermal and mechanical properties of polyurethane/montmorillonite nanocomposites based on a novel reactive modifier," Polymer Degradation and Stability, vol. 86, no. 3, pp. 549-555, 2004.

[23] W. J. Choi, S. H. Kim, Y. Jin Kim, and S. C. Kim, "Synthesis of chain-extended organifier and properties of polyurethane/clay nanocomposites," Polymer, vol. 45, no. 17, pp. 6045-6057, 2004.

[24] N. Salahuddin, S. A. Abo-El-Enein, A. Selim, and O. Salah ElDien, "Synthesis and characterization of polyurethane/organomontmorillonite nanocomposites," Applied Clay Science, vol. 47, no. 3-4, pp. 242-248, 2010.

[25] A. K. Barick and D. K. Tripathy, "Preparation, characterization and properties of acid functionalized multi-walled carbon nanotube reinforced thermoplastic polyurethane nanocomposites," Materials Science and Engineering B, vol. 176, no. 18, pp. 14351447, 2011.

[26] S. Şen and G. Çayli, "Synthesis of bio-based polymeric nanocomposites from acrylated epoxidized soybean oil and montmorillonite clay in the presence of a bio-based intercalant," Polymer International, vol. 59, no. 8, pp. 1122-1129, 2010.

[27] V. M. Wik, M. I. Aranguren, and M. A. Mosiewicki, "Castor oilbased polyurethanes containing cellulose nanocrystals," Polymer Engineering and Science, vol. 51, no. 7, pp. 1389-1396, 2011.

[28] M. Zhu, S. Bandyopadhyay-Ghosh, M. Khazabi, H. Cai, C. Correa, and M. Sain, "Reinforcement of soy polyol-based rigid polyurethane foams by cellulose microfibers and nanoclays," Journal of Applied Polymer Science, vol. 124, no. 6, pp. 47024710, 2012.

[29] U. Stirna, A. Fridrihsone, B. Lazdina, M. Misane, and D. Vilsone, "Biobased polyurethanes from rapeseed oil polyols: structure, mechanical and thermal properties," Journal of Polymers and the Environment, pp. 1-11, 2012.

[30] S. Gaidukov, Polymer nanocomposites filled with nanoscale placoid particles of montmorillonite [Doctoral thesis], Riga Technical university, 2008.

[31] M. Alexandre and P. Dubois, "Polymer-layered silicate nanocomposites: preparation, properties and uses of a new class of materials," Materials Science and Engineering R, vol. 28, no. 1, pp. 1-63, 2000. 

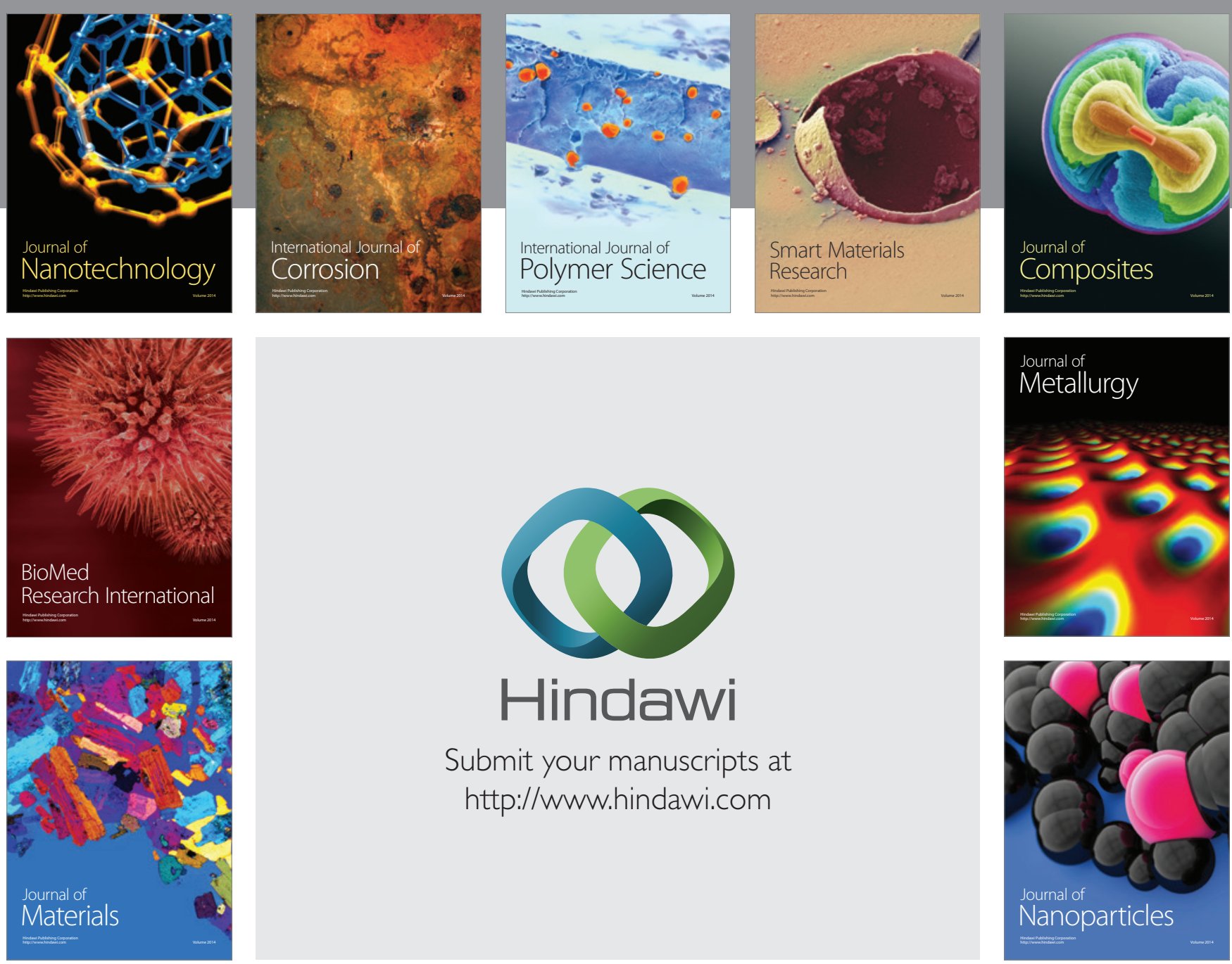

Submit your manuscripts at http://www.hindawi.com
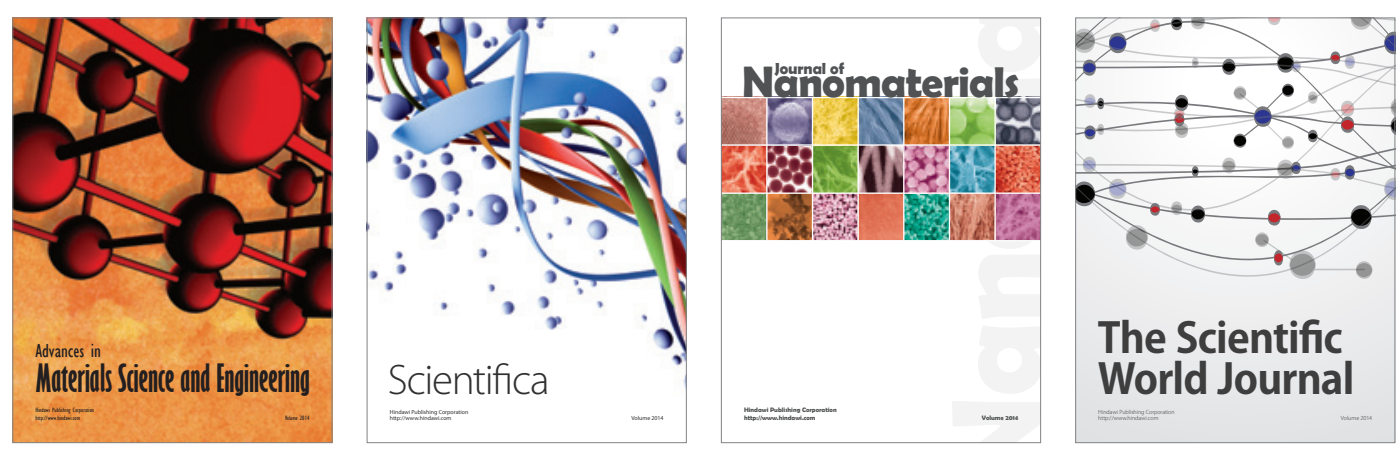

\section{The Scientific World Journal}
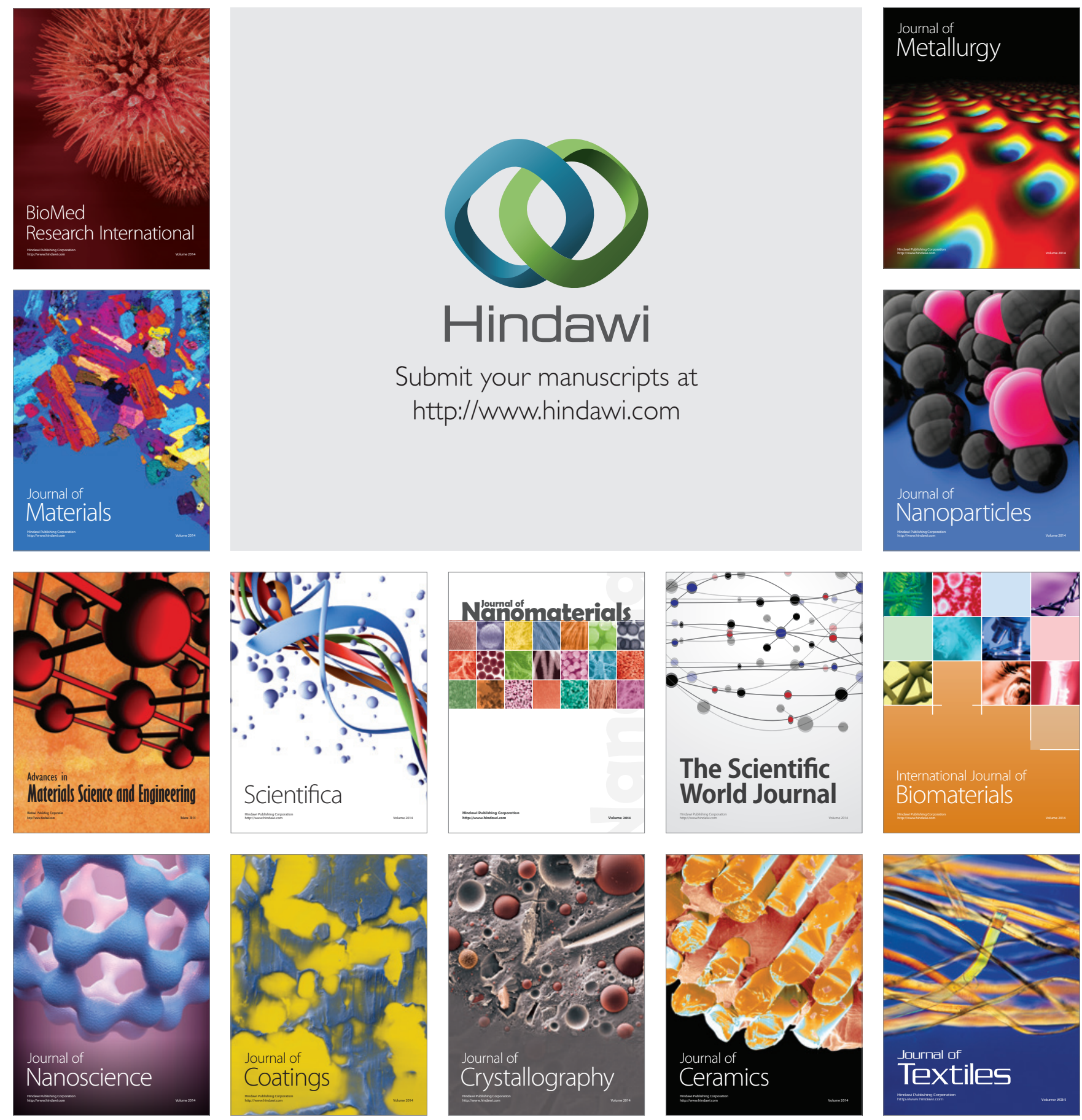